\title{
Long-term impact of preeclampsia on maternal endometrial cancer risk
}

\author{
Sara Hallum ${ }^{1}$ Anja Pinborg ${ }^{2}$ and Mads Kamper-Jørgensen ${ }^{*}, 1$ \\ ${ }^{1}$ Department of Public Health, University of Copenhagen, Oster Farimagsgade 5, Postbox 2099, DK-1014 Copenhagen, Denmark \\ and ${ }^{2}$ Department of Obstetrics \& Gynaecology, Copenhagen University Hospital, Hvidovre Hospital, DK-2650 Hvidovre, \\ Copenhagen, Denmark
}

Background: Endometrial cancer is mainly dependent on oestrogen exposure. Preeclampsia has shown to reduce oestrogen levels hence preeclampsia may affect later endometrial cancer risk.

Methods: We conducted a case-control study of 523 Danish women with endometrial cancer and 52299 controls during 1978-2010. The association between preeclampsia and later endometrial cancer was evaluated overall and according to preeclampsia onset and type of endometrial cancer in conditional logistic regression models.

Results: We observed no overall association between preeclampsia and endometrial cancer risk $(\mathrm{OR}=1.11(95 \% \mathrm{Cl} 0.68-1.81))$. This was true for all endometrial cancer subtypes. In an analysis of preeclampsia onset, however, we report a markedly increased risk of endometrial cancer following early-onset preeclampsia (OR=2.64 (95\% Cl 1.29-5.38)).

Conclusions: Although we report no obvious association between preeclampsia and endometrial cancer, studying the subset of early-onset preeclampsia may prove fruitful in further understanding the aetiology of endometrial cancer.

Endometrial cancer is the most common gynaecological malignancy affecting postmenopausal women (Purdie, 2003). Endometrial carcinogenesis is thought to be the result of increased proliferation of endometrial cells due to excess oestrogen exposure (Persson, 2000). Preeclampsia is a pregnancy-induced syndrome characterised by elevated blood pressure and protein excretion in the urine (Steegers et al, 2010), and has shown to reduce oestrogen and increase androgen and progesterone levels (Nechuta et al, 2010). This is thought to underlie the consistent finding of reduced breast cancer risk following preeclampsia (Vatten et al, 2002; Innes and Byers, 2004; Nechuta et al, 2010; Kim et al, 2013; Pacheco et al, 2015). Similarly, in the current study we hypothesised that preeclampsia would be associated with reduced risk of later endometrial cancer.

\section{MATERIALS AND METHODS}

Study population. We designed the present study as a density sampling case-control study, using data from nationwide Danish registers during the period 1978-2010. From the Danish Medical Birth Registry (Knudsen and Olsen, 1998), we identified all women who gave birth in Denmark during 1 January 1978 to 31 December
2010. We included women with singleton pregnancies ending in a live or still birth ( $\geqslant 22$ weeks of gestation), and women with no record of endometrial cancer prior to pregnancy. We randomly sampled 100 age-matched controls per case who at time of sampling had not received a diagnosis of endometrial cancer. We obtained information on date of migration and death for all cases and controls from the Danish Civil Registration system (Pedersen, 2011).

Preeclampsia. We identified maternal hospital contacts with preeclampsia occurring during any pregnancy from the Danish National Patient Register (Lynge et al, 2011). Herein, hospital contacts are coded according to the International Classification of Diseases 8th revision (ICD-8) during 1978-1993 and the 10th revision during 1994-2010. Preeclampsia hospital contacts were identified using the ICD-8 codes 637.03, 637.04, 637.09, 637.19 and 661.3, and the ICD-10 codes O14 and O15. We further subdivided preeclampsia in early-onset preeclampsia (22-33 weeks of gestation) and late-onset preeclampsia (34-44 weeks of gestation) measured in completed pregnancy weeks.

Endometrial cancer. Diagnosis of endometrial cancer was defined according to The International Classification for Oncology 3rd

*Correspondence: Dr M Kamper-Jørgensen; E-mail: maka@sund.ku.dk

Received 23 December 2015; revised 2 February 2016; accepted 14 February 2016; published online 10 March 2016

(c) 2016 Cancer Research UK. All rights reserved 0007 - 0920/16 
Edition (ICD-O-3) and obtained from the Danish Cancer Registry (Gjerstorff, 2011). Women with an incident diagnosis of endometrial cancer were identified using the ICD-O-3 codes C54-C54.9 and C55.9. We further subdivided women with endometrial cancer into cases with hormone-dependent Type-I endometrial cancer (ICD-O-3 codes: $8140,8380,8382,8480,8482,8560,8570)$ and hormoneindependent Type-II endometrial cancer (ICD-O-3 codes: 8310, 8441, 8460). The remaining endometrial cancer types, which are unspecified, rare, and do not share the same histological characteristics as Type-I and Type-II endometrial cancers (ICD-O-3 codes: $80103,80703,81433,82103,82463,82603,83813,84703,88003$, $88903,88913,88963,89003,89303,89313,89333,89353,89503$, $89803,91003,91053,99903,99993)$, were classified as 'Other'.

Statistical methods. We explored the association between preeclampsia and later endometrial cancer by odds ratios (OR) with 95\% confidence intervals estimated in conditional logistic regression models. Analyses were carried out using the PHREG procedure in SAS version 9.4 (SAS Institute Inc., 2008).

Further, we conducted subgroup analyses according to subtype of endometrial cancer and onset of preeclampsia. All analyses were adjusted for age at first birth (5-year age groups), parity $(1,2, \geqslant 3)$, diabetes (yes $v s$ no) and maternal educational attainment (primary education, upper secondary education, vocational education, short cycle higher education, university or higher education).

\section{RESULTS}

During the study period, a total of 523 women were diagnosed with endometrial cancer and a total of 52229 age-matched women

Table 1. Characteristics of cases and controls according to

age at time of sampling, age at first birth, parity, diabetes and the mother's educational attainment. Numbers (column percentage)

\begin{tabular}{|c|c|c|}
\hline & Cases $(n=523)$ & Controls $(n=52299)$ \\
\hline \multicolumn{3}{|c|}{ Age at time of sampling (years) } \\
\hline$<51$ & $272(52.0)$ & $27200(52.0)$ \\
\hline$\geqslant 51$ & $251(48.0)$ & $25099(48.0)$ \\
\hline \multicolumn{3}{|c|}{ Age at first birth (years) } \\
\hline$<25$ & $140(26.8)$ & $11724(22.4)$ \\
\hline $25-29$ & $193(36.9)$ & $19420(37.1)$ \\
\hline 30-34 & $114(21.8)$ & $13402(25.6)$ \\
\hline$\geqslant 35$ & $76(14.5)$ & $7753(14.8)$ \\
\hline \multicolumn{3}{|l|}{ Parity } \\
\hline 1 & $186(35.6)$ & $14429(27.6)$ \\
\hline 2 & $237(45.3)$ & 25778 (49.3) \\
\hline$\geqslant 3$ & $100(19.1)$ & $12092(23.1)$ \\
\hline \multicolumn{3}{|l|}{ Diabetes } \\
\hline Yes & $18(3.4)$ & $882(1.7)$ \\
\hline No & $505(96.6)$ & $51417(98.3)$ \\
\hline \multicolumn{3}{|l|}{ Education } \\
\hline University or higher & $38(7.3)$ & $3889(7.5)$ \\
\hline Short cycle higher & $139(26.8)$ & $15677(30.3)$ \\
\hline Vocational & $177(34.2)$ & $17465(33.8)$ \\
\hline Upper secondary & $20(3.9)$ & $2159(4.2)$ \\
\hline Primary & $144(27.8)$ & $12469(24.1)$ \\
\hline
\end{tabular}

without endometrial cancer were sampled as controls. At time of endometrial cancer diagnosis, the mean age of women was 50 (range 24-68) years (data not shown).

Table 1 shows characteristics of the studied cases and controls. Compared with controls, cases were more often primiparous and more often had diabetes. Cases and controls were on average 29 years old when delivering their first child (28.8 years (range: 17-46) and 29.2 years (range-15-52), respectively; data not shown. Cases had given birth to an average of 1.89 children (range 1-7), while the similar figure for women in the control group was 2.03 (range 1-13; data not shown).

Table 2 shows the prevalence of preeclampsia among cases and controls and the association between preeclampsia and later endometrial cancer overall and according to cancer subsets. Having had a pregnancy complicated by preeclampsia was observed in 18 (3.4\%) cases and 1515 (2.9\%) controls, which corresponds to an adjusted overall OR of 1.11 (95\% CI $0.68-1.81$ ). In the cancer subgroup analyses, we found women with preeclampsia to have a $19 \%$ increased risk of Type-I endometrial cancer $(\mathrm{OR}=1.19,95 \%$ CI: 0.70-2.05). No women with preeclampsia developed Type-II endometrial cancer during the study period, why the association was not estimable, and we observed no association between preeclampsia and other types of endometrial cancer $(\mathrm{OR}=1.01$, 95\% CI 0.32-3.20).

Table 3 shows the prevalence of preeclampsia stratified according to onset of preeclampsia among cases and controls and associated OR (95\% CI). Women with early-onset preeclampsia had a markedly increased risk of later endometrial cancer, while women with late-onset preeclampsia tended to have a slightly reduced risk compared with women without preeclampsia $(\mathrm{OR}=2.64,95 \%$ CI $1.29-5.38$ and $\mathrm{OR}=0.73,95 \%$ CI $0.38-1.42$, respectively).

\section{DISCUSSION}

In summary, we report that preeclampsia did not alter the overall risk of endometrial cancer. This finding is in agreement with a Swedish cohort study reporting no obvious association between preeclampsia and risk of endometrial cancer (Mogren et al, 2001). We set out with the anticipation that women with preeclampsia would be at reduced risk of later endometrial cancer analogous to what is observed in breast cancer (Innes and Byers, 2004; Nechuta et al, 2010; Kim et al, 2013; Pacheco et al, 2015). We observed no such risk reduction, not even in analyses confined to women with the oestrogen-sensitive endometrial cancer subtype I.

Evidence suggests that breast cancer is sensitive to a combination of oestrogens and progesterone (Anderson, 2002), whereas endometrial cancer is generally dependent solely on oestrogen exposure (Henderson and Feigelson, 2000), which may explain the differing effects of preeclampsia on breast and endometrial cancer risk. Alternatively, the lack of an overall association may reflect that our exposure is subject to misclassification or due to residual confounding. Moreover, preeclampsia may carry other risks that outweigh the positive consequences of hormonal fluctuations.

Table 2. Preeclampsia and risk of endometrial cancer overall and according to type of endometrial cancer

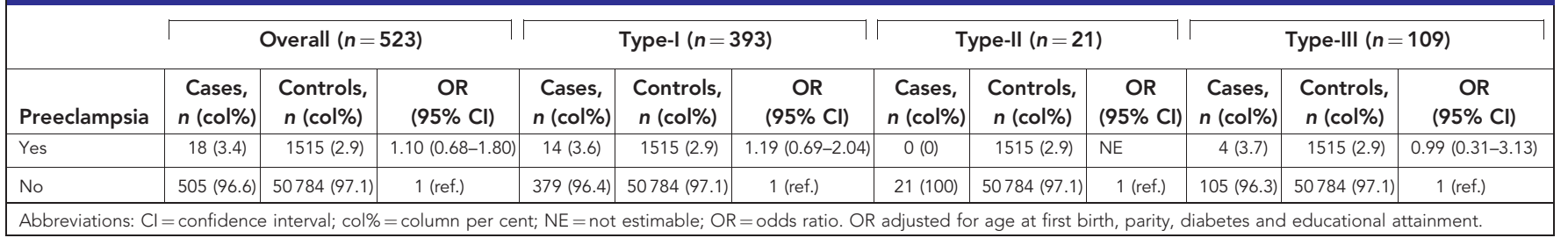


Table 3. Preeclampsia and endometrial cancer risk according to onset of preeclampsia

\begin{tabular}{|l|c|c|c|}
\hline Preeclampsia & $\begin{array}{c}\text { Cases, } \\
\mathbf{n}(\mathbf{c o l} \%)\end{array}$ & $\begin{array}{c}\text { Controls, } \\
\boldsymbol{n} \text { (col\%) }\end{array}$ & OR (95\% Cl) \\
\hline Early onset & $9(1.7)$ & $292(0.6)$ & $2.62(1.28-5.34)$ \\
\hline Late onset & $9(1.7)$ & $1223(2.3)$ & $0.73(0.38-1.42)$ \\
\hline No & $505(96.6)$ & $50784(97.1)$ & 1 (ref.) \\
\hline
\end{tabular}

Abbreviations: $\mathrm{Cl}=$ confidence interval; col\%=column per cent; $\mathrm{OR}=$ odds ratio. $\mathrm{OR}$ adjusted for age at first birth, parity, diabetes and educational attainment.

Women with a mild degree of preeclampsia who did not require hospital treatment were misclassified as unexposed in our study. The diagnosis of preeclampsia, however, did not depend on future diagnosis of endometrial cancer. Consequently, this non-differential misclassification of exposure might have led us to underestimate any true association of preeclampsia and subsequent endometrial cancer.

Information on important confounders, including hormonereplacement therapy (HRT) and body mass index (BMI), physical activity and smoking was not available in the health registers. High BMI markedly increases the risk of endometrial cancer (Lindermann et al, 2008), as well as preeclampsia (Duckitt and Harrington, 2005). Therefore, we cannot reject the possibility that the increased risk of endometrial cancer observed among women with early-onset preeclampsia is in part due to confounding from BMI. High BMI and diabetes are strongly correlated (Hossain et al, 2007) and the association between diabetes and endometrial cancer is largely explained by body weight (Luo et al, 2014). Thus, we argue that adjustment for diabetes indirectly and partially also adjusted our results for BMI. HRT increases the risk of endometrial cancer (Beral et al, 2005), and is also considered a risk factor for developing cardiovascular disease (Chong and Lip, 2002). Also, independent of HRT, preeclampsia has been associated with an increased risk of cardiovascular disease (Bellamy et al, 2007). Therefore, women with preeclampsia will less often have been offered HRT treatment at menopause compared with women without preeclampsia in the present study. Lack of adjustment for HRT has left our estimated association between preeclampsia and later endometrial cancer conservative. Physical activity and smoking protect against preeclampsia (Magnus et al, 2008; Sibai et al, 1997) and endometrial cancer (Moore et al, 2010; Setiawan et al, 2013; Terry et al, 2002). Residual confounding by these variables may likely underestimate any true association.

Strengths of the current study include the prospective nature of data, a low risk of selection bias and the large study population. By design, we ensured that the exposure predated the outcome and matching controls to cases on exact age with 1-day precision eliminated confounding from age. Also, because controls were randomly selected among all Danish women giving birth, we markedly reduced the risk of selection bias.

In conclusion, we observe an elevated risk of later endometrial cancer following preeclampsia, but only among women with earlyonset preeclampsia. We encourage others with additional data on BMI and HRT to pursue the possibility that this is not an incidental finding.

\section{ACKNOWLEDGEMENTS}

We thank Anne-Marie Nybo Andersen for making register data available to us and for sharing obstetric and epidemiological knowledge. Also, we thank Tina Kold Jensen for input on clinical aspects. The study was supported by Department of Public Health, the University of Copenhagen.

\section{CONFLICT OF INTEREST}

The authors declare no conflict of interest.

\section{REFERENCES}

Anderson E (2002) Progesterone receptors-animal models and cell signalling in breast cancer. The role of oestrogen and progesterone receptors in human mammary development and tumorigeneis. Breast Cancer Res 4 : 197-201.

Bellamy L, Casas J, Hingorani A, Williams D (2007) Pre-eclampsia and risk of cardiovascular disease and cancer in later life: systematic review and meta-analysis. BMJ 335: 974.

Beral V, Bull D, Reeves G. Million Women Study Collaborators (2005) Endometrial cancer and hormone-replacement therapy in the million women study. Lancet 365: 1543-1551.

Chong A, Lip G (2002) Hormone replacement therapy and cardiovascular risk. Treat Endocrinol 1: 95-103.

Duckitt K, Harrington D (2005) Risk factors for pre-eclampsia at antenatal booking: a systematic review of controlled studies. BMJ 330: 565 .

Gjerstorff M (2011) The Danish Cancer Registry. Scand J Public Health 39: $42-45$.

Henderson B, Feigelson H (2000) Hormonal carcinogenesis. Carcigonesis 21: 427-433.

Hossain P, Kawar B, El Nahas M (2007) Obesity and diabetes in the developing world-a growing challenge. N Engl J Med 356: 213-215.

Innes K, Byers T (2004) First pregnancy characteristics and subsequent breast cancer risk among young women. Int J Cancer 112: 306-311.

Kim JS, Kang EJ, Woo OH, Park KH, Woo SU, Yang DS, Kim AE, Lee JB, Kim YH, Kim JS, Seo JH (2013) The relationship between preeclampsia, pregnancy-induced hypertenstion and maternal risk of breast cancer: a meta-analysis. Acta Oncol 52: 1643-1648.

Knudsen L, Olsen J (1998) The Danish Medical Birth Registry. Scand J Public Health 45: 320-323.

Lindermann K, Vatten L, Ellstrøm-Engh M, Eskild A (2008) Body mass, diabetes and smoking, and endometrial cancer: a follow-up study. Br J Cancer 98: 1582-1585.

Luo J, Chen C, Chlebowski R, Garcia L, Kuller L, Regier M, Wactawski-Wende J, Margolis KL (2014) Association between diabetes, diabetes treatment and risk of developing endometrial cancer. Br J Cancer 111: 1432-1439.

Lynge E, Sandegaard J, Rebolj M (2011) The Danish National Patient Register. Scand J Publich Health 39(7 Suppl): 30-33.

Magnus P, Trogstad L, Owe K, Olsen S, Nystad W (2008) Recreational physical activity and the risk of preeclampsia: A prospective cohort of Norwegian women. Am J Epidemiol 168: 952-957.

Mogren I, Stenlund H, Högeberg U (2001) Long-term impact of reproductive factors on the risk of cervical, endometrial, ovarian and breast cancer. Acta Oncol 40: 849-854.

Moore S, Gierach G, Matthews C (2010) Physical activity, sedentary behaviours, and the prevention og endometrial cancer. $\mathrm{Br} J$ Cancer 103: 933-938.

Nechuta S, Paneth N, Velie E (2010) Pregnancy characteristics and maternal breast cancer risk: a review of the epidemiologic literature. Cancer Causes Control 21: 1-33.

Pacheco N, Nybo A, Kamper-Jørgensen M (2015) Preeclampsia and breast cancer: the influence of birth characteristics. Breast 24: 613-617.

Pedersen C (2011) The Danish Civil Registration System. Scand J Public Health 39(7 Suppl): 22-25.

Persson I (2000) Estrogens in the causation of breast, endometrial and ovarian cancers-evidence and hypotheses from epidemiological findings. J Steroid Biochem Mol Biol 74: 357-364.

Purdie D (2003) Epidemiology of endometrial cancer. Best Pract Res Clin Obstet Gynaecol 15: 217-220.

SAS Institute Inc. (2008) SAT/STAT Software Release 9.3. SAS Institute Inc: Cary, NC, USA.

Setiawan VW, Yang HP, Pike MC, McCann SE, Yu H, Xiang YB, Wolk A, Wentzensen N, Weiss NS, Webb PM, van den Brandt PA, van de Vijver K, Thompson PJ, Australian National Endometrial Cancer Study Group, Strom BL, Spurdle AB, Soslow RA, Shu XO, Schairer C, Sacerdote C, Rohan TE, Robien K, Risch HA, Ricceri F, Rebbeck TR, Rastogi R, Prescott J, Polidoro S, Park Y, Olson SH, Moysich KB, Miller AB, 
McCullough ML, Matsuno RK, Magliocco AM, Lurie G, Lu L, Lissowska J, Liang X, Lacey Jr JV, Kolonel LN, Henderson BE, Hankinson SE,

Híkansson N, Goodman MT, Gaudet MM, Garcia-Closas M, Friedenreich CM, Freudenheim JL, Doherty J, De Vivo I, Courneya KS, Cook LS, Chen C, Cerhan JR, Cai H, Brinton LA, Bernstein L, Anderson KE, Anton-Culver H, Schouten LJ, Horn-Ross PL (2013) Type I and II Endometrial Cancers: Have They Different Risk Factors? J Clin Oncol 31: 2607-2620.

Sibai BM, Ewell M, Levine RJ, Klebanoff MA, Esterlitz J, Catalano PM, Goldenberg RL, Joffe G (1997) Risk factors associated with preeclampsia in healthy nulliparous women. The Calcium for Preeclampsia Prevention (CPED) Study Group. Am J Obstet Gynecol 177: 1003-1010.

Steegers EAP, Dadelszen P, von, Duvekor JJ, Pijnenborg R (2010) Pre-eclampsia. Lancet 376: 631-644.

Terry P, Miller A, Rohan TE (2002) A prospective cohort study of cigarette smoking and the risk of endometrial cancer. $\mathrm{Br} J$ Cancer 86: 1430-1435.

Vatten L, Romundstad P, Trichopoulos D, Skjærven R (2002) Preeclampsia in pregnancy and subsequent risk for breast cancer. $\mathrm{Br}$ J Cancer $\mathbf{8 7}$ : 971-973. 